\title{
Aquagenic wrinkling of the palms
}

\author{
Marian Katz MD, Yuval Ramot MD MSc
}

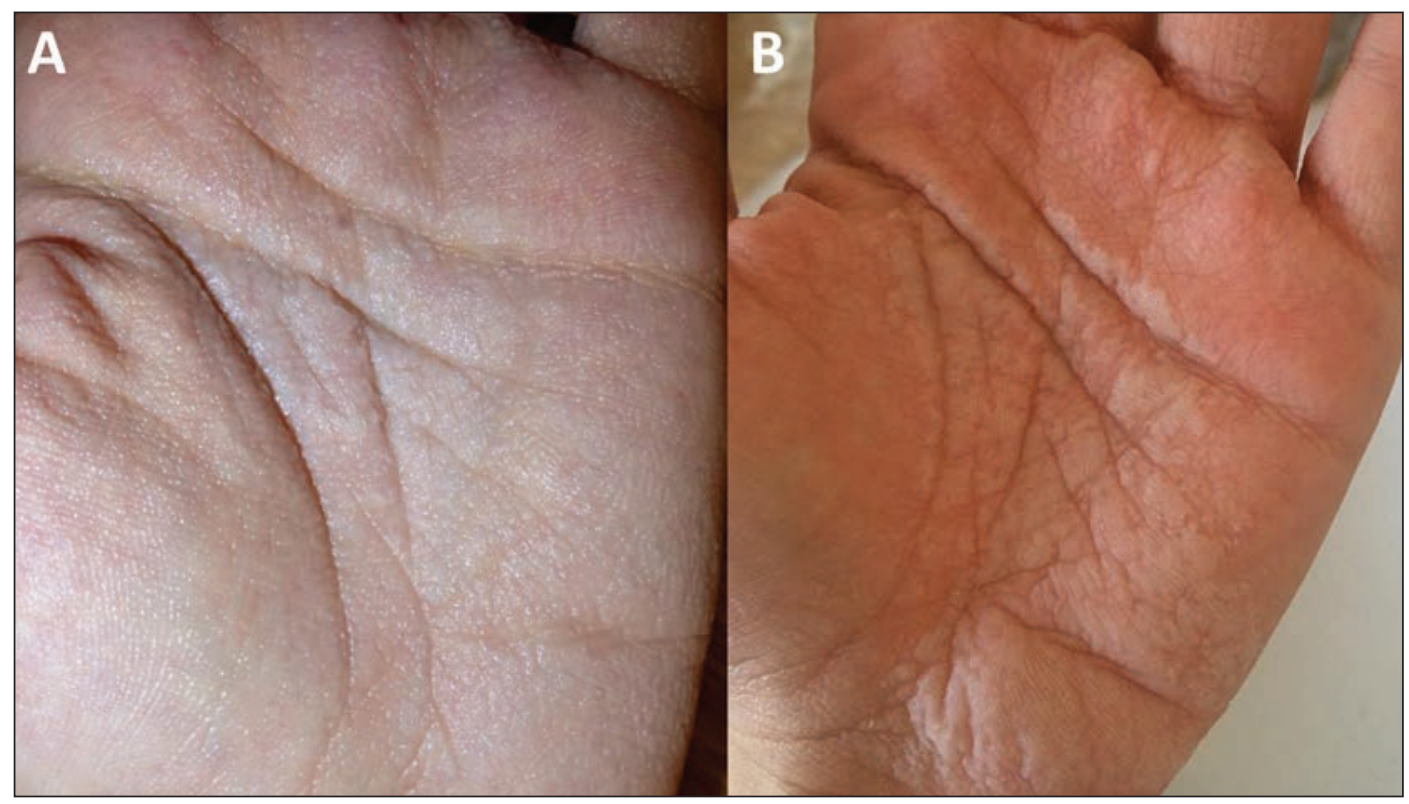

Figure 1: (A) White, slightly translucent papules on the left palm of a 23-year-old woman. (B) The papules became enlarged and edematous after a brief immersion in water, with excess wrinkling of the skin.

A healthy 23-year-old woman presented with a six-month history of white lesions on her palms. The lesions would swell after being in water for 15 minutes and return to baseline 10-15 minutes after drying. The patient did not take medications except for oral contraceptive pills, and she was not aware of a family history of similar complaints. Physical examination showed white, slightly translucent papules on her palms (Figure 1A), which became swollen and edematous after a short period of water contact, accompanied by excessive wrinkling of the palms (Figure 1B). We diagnosed aquagenic wrinkling of the palms. Genetic testing showed a heterozygous mutation $(\triangle \mathrm{F} 508)$ in the cystic fibrosis transmembrane conductance regulator gene (CFTR).

Aquagenic wrinkling of the palms is a rare disorder characterized by the appearance of papules and wrinkling of the palms after contact with water. ${ }^{1}$ The lesions may be accompanied by pruritus or a burning sensation and typically disappear 10-60 minutes after drying. Hot water hastens their appearance. The condition has been linked to several disorders, including focal hyperhidrosis, atopic dermatitis and Raynaud phenomenon, and to the use of COX-2 inhibitors. ${ }^{2}$ The strongest association is with cystic fibrosis, an autosomal recessive disease caused by mutations in CFTR. Aquagenic wrinkling of the palms is considered a clinical sign of cystic fibrosis and is seen in as many as $80 \%$ of people with the disease. ${ }^{2,3}$ It has also been reported in people who are cystic fibrosis carriers, although the sign takes longer to manifest following water immersion in this population. ${ }^{4} \mathrm{Ge}$ netic testing should be performed in patients who present with aquagenic wrinkling of the palms.

\section{References}

1. Weibel L, Soinas R. Aquagenic wrinkling of palms in cystic fibrosis. N Engl J Med 2012;366:e32.

2. Arkin LM, Flory JH, Shin DB, et al. High prevalence of aquagenic wrinkling of the palms in patients with cystic fibrosis and association with measurable increases in transepidermal water loss. Pediatr Dermatol 2012;29:560-6.

3. Garçon-Michel N, Roguedas-Contios AM, Rault G, et al. Frequency of aquagenic palmoplantar keratoderma in cystic fibrosis: A new sign of cystic fibrosis? Br J Dermatol 2010;163:162-6.

4. Gild R, Clay CD, Morey S. Aquagenic wrinkling of the palms in cystic fibrosis and the cystic fibrosis carrier state: a case-control study. Br J Dermatol 2010;163:1082-4.
Competing interests: None declared.

This article has been peer reviewed.

The authors have obtained patient consent.

Affiliations: Private practice (Katz); Department of Dermatology (Ramot), Hadassah - Hebrew University Medical Center, Jerusalem, Israel

Acknowledgement: The authors thank Prof Abraham Zlotogorski for his valuable advice and help in the preparation of this manuscript.

Correspondence to:

Yuval Ramot, yramot@hadassah.org.il

CMAJ 2015. DOI:10.1503 /cmaj.150074 